\title{
Evaluation of Academic Digital Libraries
}

\author{
Dr. Devendra Kumar Gautam \\ Asst.professor(Library \& Information Science)Maharana Pratap Govt.College Sikandra Rao \\ Hathras (U.P.)
}

\begin{abstract}
The purpose of this report is to provide an overview of works on digital library evaluation that included data:construct that were evaluated; context in which evaluation were conducted;criteria that were chosen as a basis for evaluation, and methods that were used. Evaluation of digital libraries is not widely practiced. The corpus in this analysis represents the majority of efforts in digital library evaluation that contain data. Conclusions, among others, speculate as to the reasons for a relatively low presence of evaluation in digital library research and practice.
\end{abstract}

Introduction To Digital Libraries: Digital libraries have a short history. While a discussion about digital libraries, under various names, started in the 1960s, it wasn't till the start or even mid of 1990s that the research, development and practice related to digital libraries really took off. The growth was phenomenal. Bernie Hurley the Director for Library Technologies at U.C.Berkeley, has drawn the distinction between Traditional Library Automation and Digital Libraries.Hurley notes that "Digital Libraries are different in that they are designed to support the creation,maintenance,management,access to,and preservation of digital contents." The emergence of digital library mirrors the growth of e-learning(or distance learning) as the virtual alternative to traditional school attendance.

Hundreds of research projects were devoted to great many aspects of digital libraries in great many countries, and more are reported each year. Everything about digital libraries is explosive, except one thing: evaluation.The literature that reports evaluation (with data) is not large, because there are not that many evaluation efforts around. The proceedings of the two major conferences on digital libraries, the European Conference on Digital Libraries (ECDL) and the Joint ACM/IEEE Conference on Digital libraries (JCDL), year in year out contain no more than $5 \%$ or so of papers or posters that have data pertaining to evaluation of whatever aspect of digital libraries. The overall research literature on digital libraries has even lesser percent devoted to evaluation containing data.

The literature on digital library evaluation can be divided in two distinct types: 1. meta or "about" literature: works that suggest evaluation concepts, models, approaches, methodologies or discuss evaluation, but do not contain data 2. object or "on" literature: works that report on actual evaluation and contain data; even data reporting is of two kinds: hard data or soft (sort-of) data (impressions).

Academic Digital Library: When digital libraries were introduced to academic world methods for education are becoming more advanced with more complexity, faster, simpler and reliable. Witten \& Bainbridge (2003) pointed out that academic digital libraries have their own purpose, research and education. Academic digital libraries are those libraries that serve the information needs of students and faculty of the college and universities. The importance of academic libraries can be seen from the need of students using it a source of information to enhance their knowledge in desired field.By definition, academic digital library plays a very crucial role in bridging students, academicians and researchers' needs on information in this boundary less information seeking era.Academic digital library may indeed support academic and intellectually try hard towards the journey of not only simply for information seeking but also for exploring, researching and growing their knowledge via adapting the information systems and human-computer-interaction technologies.

Evaluation to Academic Digital Library: This definition implies that evaluation specify what is the research process (metrics and procedures)?, what is the phenomenon (its mission, and salient characteristics)?, and the context(s) in which the phenomenon operates.Evaluation has both theoretical and practical impact in information science.Theoretical constructs such as information needs, relevance, and information transfer are debated and assessed regularly, and metrics for assessing system development and operation are crucial to continued progress in practice. Four classes of evaluation objects were defined: learners, teachers, the technical system, and the content.

Objectives of Digital Library:

- Gain access to the holdings of libraries worldwide through automated catalogs.

- Locate both physical and digitized variation of scholarly articles and books. 
- Optimize searches,simultaneously search the internet,commercial databases and library collection.

- Save search results and conduct additional processing to narrow or quality results.

- From search results,click through to access the digitized content or locate additional items of interest.

The NSF in the United States has joined with the JISC in the United Kingdom to sponsor a major research program called "Digital Libraries and the classroom:Test-beds for Transforming Teaching and Learning ". This program will promote the use of large scale,distributed digital content and advanced networking technologies for learning.

Five basic steps for Evaluation of Academic Digital Library :

1. Identify the decisions that you or others involved in your digital library enterprise must make.

2. Identify the questions that need to be addressed to inform the pending decisions.

3. Identify the evaluation methods and instruments that will be used to collect the information needed to address these questions.

4. Carry out the evaluation in a manner that is as effective and efficient as possible.

5. Report the evaluation results in an accurate and timely manner so that it can provide the information you and others need to make the best possible decisions.

Planing of Evaluation: An evaluation plan should reveal the what, how, when - where and other technical and logistical requirements of an evaluation. It provides a means of keeping the decisions, questions, and methods involved in an evaluation open to review and enhancement by all stakeholders. In addition to enabling the support of stakeholders, the process of preparing a plan helps you understand the size and scope of an evaluation project. You need this understanding to establish a meaningful time-line and a reasonable budget for the evaluation. The first step in the planning process is identifying the decisions that the evaluation should inform.

\section{What kinds of questions should you address?}

Suppose your evaluation is focused on decisions about the types of services that your digital library should include. Some of the questions that might be addressed are:

- What services are offered by other digital libraries?

- What services have patrons of your digital library requested?

-What services would your patrons be willing to pay for?

- What services would require external funding?

\section{What kinds of methods should you use?}

There are numerous evaluation methods (e.g., usability testing) and even more specific data collection strategies (e.g., keystroke analysis) that can be used within any given method.A better strategy might be:

- conduct a series of focus groups with teachers, administrators, and parents about the pros and cons of open searching by middle school students,

- review the policies established by a representative sample of school districts concerning Internet access by students, and

- review the professional library literature concerning recommendations for Internet search policies and procedures.

How should an evaluation plan be organized?

We will be organize your evaluation plan using the following sections:

- Introduction

- Background

- Stakeholders

- Purposes

- Decisions

- Questions

- Methods

- Sample

- Instrumentation

- Limitations

- Logistics

- Budget

Some important terms related to Evaluation: 
Service Evaluation: Service evaluation within a traditional library system is focused on evaluating how effective a library is in carrying out its mission (Marchionini,2000). For a digital library, the focus is very much the same: How is the digital library carrying out its mission and providing service to its users? Anyone involved in digital libraries knows that this sounds much simpler than it is. Whereas librarians working in a physical library can see users, request feedback, and observe interactions with various service functions, people who work with digital libraries lack these opportunities. Nonetheless, as described be- low, there are effective strategies that can be used for service evaluation in the virtual environment of digital libraries.

\section{How do you do a service evaluation?}

It might taking some working steps which are given below:

Step 1: Identify the different service attributes for which you want user input.

For our example some attributes might include:

- Number of hours reference librarian is available for live help

- Method of communication between librarian and patron (i.e., online chat, email, or telephone?)

- Price users are willing to pay to have a live reference librarian

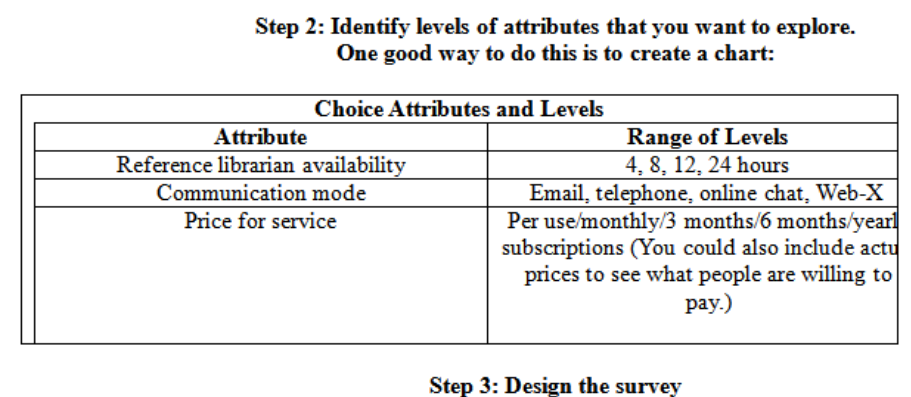

Surveys typically begin with easy questions, to help focus the participant on the subject at hand, before moving into the more "thought provoking" questions. You may want to begin your survey with questions that gather demographic information (e.g., age, position, etc.) or information about the respondent's knowledge of or use of the digital library.

\section{Step 4: Administer survey, analyze results, and present findings.}

The final steps in conducting a multi-attribute, stated-preference survey would be to administer it to the relevant group of people, analyze the results, and present your findings to the decision makers in a timely manner. Today, many surveys are administered over the WWW. This seems particularly appropriate if you are surveying typical users of a digital library. However, if you are seeking input from non-users, having the survey available via the Internet alone may introduce an unacceptable level of bias because people who are not online won't be able to access your survey. You'll need to consider alternative methods of collecting the surveys such as regular mail, telephone, or per- son-to-person.

Usability of Evaluation: Usability,in the context of digital libraries, can be defined as the effectiveness, efficiency, and personal satisfaction with which people are able to access and make productive use of the resources in a digital library. People interact with a digital library (and most other computers programs) through some sort of human-computer interface. The importance of the interface and the functionality it enables cannot be overemphasized.Usability is about much more than the "look and feel" of the digital library. The interface of a digital library should communicate its functions and navigational structure to new users with a minimum of “cognitive overload.’'Usability is not just a concern for new users.

There are many challenges that novices are bound to face, including:

- unfamiliarity with functionality of computers in general,

- lack of information-age skills such as effective search strategies, and

- unfamiliarity with the interface and functionality of the library being used.

There are numerous methods that can be used to evaluate the usability of a digital library. Usability evaluation methods can be classified as belonging to one of three categories: inspection, testing, and inquiry.

Usability "inspection" refers to a number of processes whereby experts systematically review the usability of a digital library and recommend improvements. Two such processes are described below: heuristic evaluation and 
cognitive walk through.

Usability "testing" refers to evaluative processes whereby the interface that enables human-computer interactions are systematically tested and enhanced.

Usability testing can be done in a professional usability laboratory, locally using a portable usability lab, or even with standard video equipment. Typically, usability testing involves having people follow predetermined protocols so that specific aspects of a digital library's usability can be evaluated. The "think aloud" approach to usability testing is described below in more detail.

Usability "inquiry" refers to processes that are somewhat like usability testing, except that in usability inquiry evaluators observe users working with digital libraries while doing real work rather than evaluator assigned tasks. There are a number of evaluative methods that fit within the usability inquiry framework including: field observations, focus groups, interviews, use logs, and questionnaires.

Information Retrieval: Information retrieval in the context of digital library evaluation is defined as finding the information (e.g., a text document, a media object, or a fact) that a user is seeking.Information retrieval evaluation is twofold, user-oriented and systems-oriented. From the systems perspective, information retrieval evaluation is focused on evaluating the effectiveness and efficiency of the retrieval system that is at the core of any digital library.

Bibliometric Evaluation: Bibliometric is a quantitative research method widely used in library and information science (Borgman, 1990). Its most popular applications are in fields such as the sociology of science and the study of scholarly communications.Bibliometric evaluation in the context of digital libraries is a relatively novel approach whereby bibliometric techniques are applied to determine the impact and rankings of documents and journals for the users of a digital library. Data collected using bibliometric methods can be used to inform decisions regarding acquisitions for the collection, organization of the collection, and services provided.Another area of bibliometric research involves citation and co-citation analyses.Citation and co-citation analysis statistics can be helpful in providing information about the value of objects within the digital library collection.

Transaction Log Analysis: Transaction log analysis is a way to track unobtrusively how users are using a digital library. As an evaluator, you may wish to analyze transaction log information as part of an overall evaluation aimed at obtaining a deeper understanding of how users are navigating through your digital library, which resources they access, and any search problems they encounter. Log analysis alone usually requires too much inference, but it provides important information that may be explained with the additional data obtained from interviews, surveys, and observations.

Survey methods: Survey methods are the most widely used data collection technique in evaluation, so much so that some people seem to equate evaluations with surveys. Surveys enable you to collect information concerning a wide range of aspects of digital libraries, especially the attitudes people have toward them and their opinions about the various advantages and disadvantages of digital libraries.In a general sense, survey methods encompass several major data collection strategies, including surveys of existing records, questionnaires, interviews, and focus groups.

Surveys are a way of collecting information to help you describe, compare, or explain knowledge, attitudes, and behaviors related to digital library use. Most often, within digital library evaluation, surveys are used to address issues that relate to user-centered concerns. Thus, the information derived from surveys can be used to inform decisions that will relate to issues relevant to users. Surveys are a good way to gather information about users:

- Previous or current behaviors

- Attitudes

- Beliefs

- Level of satisfaction

Interviews\& Focus Groups: Interviewing is a frequently used data collection method in evaluations of all kinds. In the context of digital library evaluation, interviews can serve to meet a variety of goals, such as measuring user satisfaction levels, getting user feedback, seeking user input, etc. Interviews can be conducted on a one-on-one basis, or in group settings. In the latter settings, interviews are often called focus groups. Interviews and focus groups can be used as part of a number of other evaluation methods described elsewhere in this Guide such as with usability testing and service evaluation. While interviews conducted in a group setting are often called focus groups.

Observations: Observations are controversial evaluation methods because many people view them as too 
subjective, as noted in the quote above from the evaluation guru, Michael Quinn Patton. rigorous, disciplined observations are essential to the research conducted in social science fields such as anthropology and sociology as well as in nature sciences such as zoology and entomology. Observations also have a long history as an evaluation method. Observations may seem to have limited applicability within the context of digital libraries, they can have important utility as well.Observation is a data collection method used to gather detailed information about a situation or event. Observation data is used to describe the setting, activities, participants, and the meaning of the observations from the observer's perspective (Patton, 2002). Observation data should be factual, accurate, and detailed, but not so detailed as to include irrelevant or trivial information that makes the description difficult to under- stand. Observational methods are ideal for gathering data related to user-centered issues, such as the usability of your digital library and also ideal for providing information about the impact and uses of your digital library in real-life settings.

Experiments: Experimental methods, usually associated with the "hard sciences" such as physics and chemistry, can also be used as a method within the context of evaluating digital libraries.For decades, experimental methods have been held up as the "gold standard" for evaluation by some experts for whom every other approach is viewed as inferior (Campbell \& Stanley, 1966).

Evaluation reporting: Evaluations may be planned and implemented with great care and expertise, but unless they are reported in an accurate and timely manner, they will have been fruitless exercises. Evaluations are not ends in themselves, but a means to better decision making. Unless digital library decision makers (funding agency officers, advisory panels, policy committees, administrators, and so forth) receive credible information provided by an evaluation at the times when critical decisions must be made, the evaluation might as well have never been done in the first place.

\section{Characteristics of good reporting}

Reporting an evaluation is as much about telling the "story" of the evaluation in a convincing manner as it is about rendering sophisticated tables, charts, and statistical analyses. It should explain the unique nature of the digital library being evaluated. Include hot links to the library if the report is digital or screen captures that illustrate its features if the report is a print document. Strive to give the reader a feel for the digital library. At a minimum, an evaluation report should answer the following stakeholder questions:

-What is the background of this digital library? Who created it? How is it funded? Who does it serve? What are its future prospects?

- Why is the purpose of the evaluation? What decisions are the results intended to inform? What questions were addressed?

- What methods were used? What is the alignment among decisions, questions, and methods? How were evaluation participants recruited?

- What worked as planned? What was changed during the implementation of the evaluation? What limitations exist that must be taken into account when reviewing the results?

- What were the results? How do the results align with the questions and decisions? How do different groups of stakeholders interpret the results?

-What recommendations can be made based upon the results? What are the anticipated outcomes of making different decisions? What trade-offs, if any, are evident?

[1] Arms, W. (2000). Digital libraries. Cambridge, MA: MIT Press. [online]: http://www.cs.cornell.edu/wya/DigLib/index.html [24Dec2007]

[2] Bertot, J. C., McClure, C. R., \& William, E. M. (2004). Assessing Digital Libraries: Evaluation Strategies, Practices, and Issues. Proceedings of the Annual Meeting- American Society for Information Science, vol 41 p:561. [online] http://www.kc.tsukuba.ac.jp/dlkc/e-proceedings/papers/dlkc04pp72.pdf [24Dec2007].

[3] Bertot, J. C., Snead, J. T., Jaeger, P. T. \& McClure, C. R. (2006) Functionality, usability, and Accessibility Iterative user-centered evaluation strategies for digital libraries. Performance Measurement and Metrics, $7(1), 17-28$.

[4] Blandford, A. \& Buchanan, G. (2003). Usability of digital libraries: A source of creative tensions with technical developments. [online] http:// www.cs.waikato.ac.nz/ grbuchan/Publications.html [24Dec2007]

[5] Kling, R. and Elliott, M. (1994). Digital Library Design for Usability. Proceedings of the First Annual Conference on the Theory and Practice of Digital Libraries, June 19-21, College Station, Texas, USA. 
online] http://www.csdl.tamu.edu/old/DL94/ [14Jul2009]

[6] Duncker, E., Theng, Y. L. \& Mohd-Nasir, N. (2000), "Cultural usability in digital libraries", Bulletin of the American Society for Information Science, Vol. 26 No. 4, pp.21-2, URL: www.asis.org/Bulletin/May-00/ duncker_et_al.html [11May2009]

[7] Ferreira, S. M. \& Pithan, D. N. (2005). Usability of digital libraries: A study based on the areas of information science and human-computer- interaction. [online] www.emeraldinsight.com/1065075X.htm [2Ju12008]

[8] Fuhr, N., Hansen, P., Mabe, M., Micsik, A., \& Sölvberg, I. (2001). Digital libraries: a generic classification and evaluation scheme. In P. Constantopoulos, \& I. So"lvberg (Eds.), Proceedings of ECDL'01 (pp.187- 199). Darmstadt, Germany.

[9] Goh, D.H-L., Chua, A., Khoo, D.A., Khoo, E.B-H., Mak, E.B-T., Ng, M.W-N. (2006). A checklist for evaluating open source digital library software. Online Information Review, 30(4), 360-379.

[10] Goncalves, M.A., Moreira, B.L, Fox, E.A. \& Watson, L.T. (2007). 'What is a good digital library?'- A quality model for digital libraries. Information Processing and Management, 43,.1416-1437.

[11] Abbas, J., Norris, C. \& Soloway, E. (2002). Middle school children's use of the ARTEMIS digital library. Proceedings of the Second ACM/IEEE-CS Joint Conference on Digital Libraries, 98-105.

[12] Adams A, \& Blandford, A. (2001). Digital libraries in a clinical setting: friend or foe? Research and advanced technology for digital libraries Proceedings of the 5th European Conference on Digital Libraries, ECDL'01, 214- 224.

[13] Bainbridge, D., Dewsnip, M. and Witten, I.H. (in print) Searching digital music libraries. Information Processing \& Management. Retrieved Sept. 23, 2004 from http://www.sciencedirect.com/

[14] Cornell University (1999). MESL technical report. Retrieved Sept. 24, 2004 from http://cidc.library.cornell.edu/gateway.htm

[15] Covey, D.T. (2002). Usage and usability assessment: library practices and concerns. Washington, D.C.: Digital Library Federation Council on Library and Information Resources. Retrieved 4/12/2004 from http://www.clir.org/pubs/reports/pub105/contents.html

[16] Cox, I.J., Miller, M.L., Minka, T.P., Papathomas, T.V. \& Yianilos, P.N. (2000). The Bayesian image retrieval system, PicHunter: Theory, Implementation and Psychophysical experiments. IEEE Transactions on Image Processing, 9(1): 20-37.

[17] Dillon, A. (1999?). Evaluating on time: a framework for the expert evaluation of digital interface usability. Retrieved 4/12/2004 from http://www.ischool.utexas.edu/ adillon/publications/evaluating.html

[18] Dorward, J., Reinke, D. \& Recker, M. (2002). An evaluation model for a digital library service tool. Proceedings of the 2nd ACM/IEEE-CS Joint Conference on Digital Library, 322-323

[19] Entlich, R., Garson, L., Lesk, M., \& Normore, L. et al. (1996). Testing a digital library: user response to the CORE project. Library Hi Tech, 14 (4): 99-118.

[20] Fox, E.A., Hix, D., et al. (1993). Users, user interfaces, and objects: Envision, a digital library. Journal of the American Society for Information Science and Technology, 44 (8): 480-491.

[21] Hartland-Fox, B., \& Dalton, P. (2003). EVALUEd-an evaluation model for e-library developments, Ariadne, 31. Retrieved June 1, 2003, from http://www.ariadne.ac.uk/issue31/evalued/.

[22] Hill, L.L., Carver, L. et al. (2000). Alexandria Digital Library: user evaluation studies and system design. Journal of the American Society for Information Science and Technology, 51 (3): 246-259.

[23] Hill, L.L., Dolin, R., et al. (1997). User evaluation: summary of the methodologies and results for the Alexander Digital Library, University of California at Santa Barbara. In C. Schwartz et. (Eds.) Proceedings of the American Society for Information Science (ASIS) Annual Meeting,.225-243, 369).

[24] Huang, Z., Chung, W.Y., Ong, T.H. \& Cheng, H.C. (2002). A graph-based recommendation system for digital library. Proceedings of the Second ACM/IEEE-CS Joint Conference on Digital Libraries,.65-73.

[25] Huxley, L. (2002). Renardus: following the Fox from project to service. Research and Advanced Technology for Digital Libraries: Proceedings of the Second European Conference, ECDL'02, 218-229.

[26] Janssen, Olaf (2004) The European library user survey of Gabriel, Gateway to Europe's National Libraries. Retrieved September 2, 2004, from http://www.bl.uk/gabriel/index.html

[27] Jewell, T. D. (1998). The ARL "investment in electronic resources" study: Final report to the council on library and information resources. Retrieved April 13, 2003, from http://www.arl.org/stats/specproj/jewell.html

[28] Jones, M.L.W., Gay, G.K. \& Rieger, R.H. (1999). Project Soup: comparing evaluations of digital collection efforts. D- Lib Magazine, 5 (11).

[29] Jones, G.J.F., \& Lam-Adesina, A.M. (2002). An investigation of mixed-media information retrieval. Research and Advanced Technology for Digital Libraries: Proceedings of the Second European Conference, ECDL'02, 463- 478.

[30] Jones, S., Cunningham, S.J. et al (2000). A transaction log analysis of a digital library. International 
Journal of Digital Libraries, 3:152-169.

[31] Kengeri, R.; Seals, C.D.; Harley, H.D.; Reddy, H.P.; Fox, E.A., (1999). Usability study of digital libraries: ACM, IEEE- CS, NCSTRL, NDLTD. International Journal on Digital Libraries,.2, (2-3) 157-69

[32] Khoo, C.S.G., Poo, D.C.C., \& Toh, T.K. et al. (1998). E-referencer: a prototype expert system Web interface to online catalog. Research and Advanced Technology for Digital Libraries: Proceedings of the Second European Conference, ECDL'98,. 316-333.

[33] Khoo, M. (2001). Ethnography, evaluation, and design as integrated strategies: a case study from WES. ECDL'01; Proceedings of the 5th European Conference on Digital Libraries, 263-274.

[34] Kilker, J. \& Gay. G. (1998) The social construction of a digital library: A case study examining implications for evaluation. Information Technology and Libraries, 17 (2), 60-70

[35] Kwak, B.H., Jun, W., Gruenwald, L. \& Hong, S.K. (2002). A study on the evaluation model for university libraries in digital environments. Research and Advanced Technology for Digital Libraries: Proceedings of the 6th European Conference, ECDL'02, 204-217.

[36] Mackie-Mason, J.K., Riveros, J. F., Bonn, M. S., \& Lougee, W.P. (1999). A Report on the PEAK Experiment. Usage and economic behavior. D-Lib Magazine, 5 (7/8).

[37] Marchionini, G. \& Crane, G. (1994). Evaluating hypermedia and learning: Methods and results from the Perseus Project. ACM Transactions on Information Systems, 12 (1), 5-34.

[38] Marchionini, G. (2001). Evaluating digital libraries: a longitudinal \& multifaceted view. Library Trends, 49 (2): 304-333.

[39] Marchionini, G., Plaisant, C., \& Komlodi, A. (2003). The people in digital libraries: multifaceted approaches to assessing needs and impact. In: Bishop, A., van House, N. A., Buttenfield, B.P. (Eds.) Digital Library Use Social Practice in Design and Evaluation. MIT Press, 119-160.

[40] Mellucci, M. (2004). Making digital libraries effective: Automatic generation of links for similarity search across hyper- textbooks. Journal of the American Society for Information Science and Technology, 55 (5) 414-430.

[41] Melucci, M. \& Orio, N. (2004) Combining melody processing and information retrieval techniques: Methodology, evaluation, and system implementation, Journal of the American Society for Information Science and Technology, 55 (12) 1058-1066)

[42] Meyyappan, N. Foo, Schubert, and Chowdhury, G.G. (2004). Design and evaluation of a task-based digital library for the academic community. Journal of Documentation, 60 (4), 449-475.

[43] Monopoli, M., Nicholas, D. Georgiou, P. and Korfiati, M. (2002). A user-oriented evaluation of digital libraries: case study the "electronic journals" service of the library and information service of the University of Patras, Greece. Aslib Proceedings: new information perspectives, 54 (2), 103-117.

[44] Nicholas, D., Huntington, P. \& Watkinson, A. (2003). Digital journals, Big Deals and online searching behaviour: a pilot study. Aslib Proceedings: new information perspectives. 55 (1): 84-109.

[45] Orio, N. (2002). Alignment of performance with scores aimed at content-based music access and retrieval. Research and advanced technology for digital libraries: Proceedings of 6 th European conference, ECDL'02, 479-492.

[46] Paliouras, G., Papatheodorou, C., \& Karkaletsis, V. et al. (1998). Learning user communities for improving the services of information providers. Research and Advanced Technology for Digital Libraries: Proceedings of the Second European Conference, ECDL'98, 316-333.

[47] White, M.D. (2001). Digital reference services: framework for analysis and evaluation. Library \& Information Science Research, 23 (3): 211-231.

[48] Wildemuth, B.M. et al (2003). How fast is fast? Evaluating fast forward surrogates for digital video. Proceedings of the Third ACM/IEEE-CS Joint Conference on Digital Libraries,221-230.

[49] Wilson, R., Landoni, M., \& Gibb, F. (2002). Guidelines for designing electronic books. Research and Advanced Technology for Digital Libraries: Proceedings of the 6th European Conference, ECDL'02, September 16-18, 2002, Paris, France, 47-60.

[50] Yang, S.C. (2001). An interpretive and situated approach to an evaluation of Perseus Digital Libraries. Journal of the American Society for Information Science and Technology, 53 (14): 1210-1223. 